\title{
QUALITY INDICATORS IN THE TREATMENT OF ACUTE ISCHEMIC STROKE
}

\author{
Silva Andonova, Evgeniya Kalevska, Darina Georgieva-Hristova, Vania Argirova, \\ Vladina Dimitrova
}

Second Neurology Clinic, UMHAT “St. Marina”, Medical University of Varna

\begin{abstract}
Cerebrovascular diseases are a global medical and social issue because of the high morbidity, mortality and disability they cause. WHO announces 15 Mio ischemic stroke occurrences per year globally, with 5 Mio associated deaths and 5 Mio left permanently disabled. Thrombolysis (TL) with tissue plasminogen activator (rt-PA) is currently an approved differentiated pharmaco-therapeutic treatment of ischemic stroke (IS) in its acute phase. There is irrefutable evidence of better health results and efficient clinical management of ischemic strokes within an integrated therapeutic approach as a key factor for improving the functional outcome in stroke patients. Quality is one of the most widely discussed issues in the theory and practice of disease management. The rigid compliance with the standards for treatment of ischemic strokes is an indicator of high quality patient management.
\end{abstract}

Keywords: management, ischemic stroke, quality indicators

\section{INTRODUCTION}

Ischemic stroke (IS) is the fourth leading cause of death in the USA and the second in Australia after ischemic heart disease, with an approximate rate of 60000 cases per year. Mortality is higher in Central and Eastern Europe as compared to Northern, Southern and Western Europe (1), and over the past 2 years, the leaders in mortality from cerebrovascular diseases are Bulgaria, Romania, Latvia and Macedonia.

According to the National Health Information Center, in 2009 there were 50678 cases of IS, of which 95.8\% (48 551) were hospitalized. The prevalent cas-

\footnotetext{
Address for correspondence:

Silva Andonova-Atanasova

Department of Neurology and Neurosciences,

Medical University of Varna

55 Marin Drinov Str.

9002 Varna, Bulgaria

e-mail:drsilva@abv.bg
}

Received: October 19, 2015

Accepted: December 15, 2015 es are of acute ischemic stroke (AIS) - 85.6\% (43 578 case), with $51.2 \%$ of the incidents being women (2).

Thrombolysis (TL) with rt-PA is currently an approved differentiated pharmaco-therapeutic treatment of ischemic stroke (IS) in its acute phase (3).

A number of multicenter international researches confirm the therapeutic effect and safety of the Actilyse medication as compared to placebo in AIS patients: NINDS (1995), ECASS I, II, III (1995, 1999, 2003), ATLANTIS and the relatively low percentage of symptomatic intracranial hemorrhages (4).

Based on the results from these researches, and as recommended by the AHA (American Heart Association), ASO (American Stroke Association) and ESO (European Stroke Association), in 2010 the time for implementing i.v. thrombolytic was increased from 3 to 4.5 hours (5).

In Bulgaria the first TL with rt-PA was done in 2005 in the city of Plovdov (2).

There is irrefutable evidence of better health results and efficient clinical management of ischemic strokes within an integrated therapeutic approach as 
a key factor for improving the functional outcome in stroke patients $(6,7)$.

\section{AIM}

Quality is one of the most widely discussed issues in the theory and practice of disease management. The aim is to present different useful and scientifically based activities for input of quality indicators in diagnostics, treatment and rehabilitation of stroke patients.

\section{MATERIAL AND METHODS}

The present study shows international researches in which the priority is to improve the quality indicators, which must meet the requirements of the medical service users.

Quality Indicator is a measure unit for determining the level of adherence to standards in healthcare and an element in the medical aid system which helps to determine the level of the achieved result or the level of compliance to select rules and standards (8).

These indicators are used for monitoring the quality of medical and managerial activities within the healthcare system and represent and tool for data collection. There are three approaches for measuring and assessment of quality:

* The structural approach - analysis of input parameters (structure, staff qualification, professional teams);

- Process analysis - assessment of activities (promotion, prevention, prophylaxis, diagnostics, therapy and rehabilitation);

* Outcome analysis - the effect of the activities leading to a change in the patient's health status.

The measuring of quality is a complex of activities aimed at collecting information, which will confirm whether the goals of a particular program or activity have been achieved. In order to measure the quality of medical care, it is necessary to develop and implement a panel of criteria on the quality of medical care $(9,10)$.

First, quality indicators must be adhered to for all patients, except under unforeseen circumstances. Second, quality indicators have to determine how to identify in practice those patients who require specific approaches. And third, quality indicators shall relate to a specific result, to be valid and reliable, to al- low to be measured, to be variable, and the observed differences between the hospitals must come from the work at the hospital itself and not from the differences in the characteristics of the patients. Also, quality indicators may change in the process of the change of the practices of caring for the patients.

The quality indicator must meet the following characteristics:

* Be measurable (Can it be counted, written down? - e.g. an hour?);

- Be achievable (Can it be achieved in practice?);

* Be interpretable (What does its existence mean?);

* Lead to a result (Can something be done about it?);

* Be timely (Does the indicator have a short-term and long-term significance?);

* Be engaging (Do the indicators cover the work of the whole team?);

* Be balanced (Do the indicators cover the full cycle of the process?).

Results are the most valuable final criterion for quality assessment, as they reflect the useful effect of healthcare services (e.g. decrease in disability, mortality etc. rates.).

In relation with the practical sphere, particular diagnostic-therapeutic indicators have been developed. Those indicators are grouped in relation to the different quality components.

\section{RESULTS}

The work team of the European Quality Improvement Programme (EQuiP) has developed and offered for implementation the following definition of a quality indicator: „such a measurable element of practice performance, based on scientific proof, for which there is evidence or consensus that it can be used to assess quality and hence change in quality of care provided."

Therefore with the aid of the indicators, quality can be measured by establishing their presence or absence or by determining their values with each user.

The monitoring system as a step on the way to guaranteeing quality is a system of periodical data collection and data analysis of selected indicators (11). 
The Indicators are clearly formulated notices of expected quality. They can be determined for each component of the system, namely - structure, process and outcome and can be defined either on the basis of a quality or a quantity principle $(12,13)$.

In relation with the optimization of quality management in healthcare the EUPHORIC program has been implemented in the practice performance.

EUPHORIC is a multidisciplinary project co-financed by the EU for the period 2003-2008.

The basic aim of the project is to integrate the already existing practical experience and knowledge in the participating countries: Austria, Bulgaria, Finland, France, Germany, Greece, Israel, Italy, the Slovak Republic, Spain and Sweden, in order to:

* Establish a possibility for developing common indicators for outcomes in the sphere of healthcare, valid across Europe;

* Assess quantity indictors for outcomes from select medical practices by developing standardized methodology, based on extensive information, on the outcome indicators and a research on the validity of the gathered information during routine practice;

* Offer objective and transparent high quality information which is readily available to users;

* Exchange information about the quality of the standards, good practices and efficacy in healthcare.

The project's main task is assessment of healthcare systems in view of improving therapy.

The EUPHORIC project indicators referring to ischemic stroke are:

* Emergency stroke iatrogenic readmission in hospital;

* Death at the $30^{\text {th }}$ day after admission with a stroke diagnosis;

* Death during hospitalization and neurological complications as a result of carotid artery stent placement;

- Death and neurological complications at 30 days after carotid artery stent placement (14).

The so called benchmarking also plays an important role in the management of AIS.

Benchmarking is a process of measuring the operations of an organization as compared to similar operations of other organizations in view of improving process management. Another definition is: " $a$ constant systematic process of assessment of products, services and works processes of organizations which represent the best practices, aiming at improvement of the whole organization".

The benchmarking programme's priority is the development of indicators in view of giving and assessment and analysis of the practice. The development of this set of indicators stimulates the improvement of quality and will create a stimulus for constant perfecting $[17,18]$. It is difficult to identify indicators of general validity for the healthcare sector for the following reasons:

* It is difficult to measure directly the achieved results in the healthcare sector;

* The results can fall simultaneously into different spheres of reporting;

* The results are not by all means related to one only aspect of the provided care; they are rather the result of a number of phases of testing, treatment and assessment.

In 2006, the European Implementation Score (EIS) was started, relating to accounting for the differences in the quality indicators in the care and treatment of acute stroke patients in six European countries - Belgium, England, Germany, Sweden, Spain and Scotland. The results were published in Stroke journal in 2012 (15).

Over 123 indicators have been identified in the scope of managing AIS (91 process related indicators; 24 with results, 8 structural indicators) (15).

The anticoagulants in patients with rhythmconduction disturbance on the neuroimaging tests were the only quality indicators used all around (16). Thirteen quality indicators were used in at least two countries. The recorded substantial differences at the audit in the different centres and countries were only related to the process of developing the quality indicators.

The conclusions from the research show that there is a great variety in the measuring of the efficiency in the care for stroke patients in Europe, which hinders the comparability of the indicators. Common indicators are needed for determining the quality indicators which have to be accepted and validated in Europe (17). 
Figure 1 shows the quality indicators in the project participating countries.

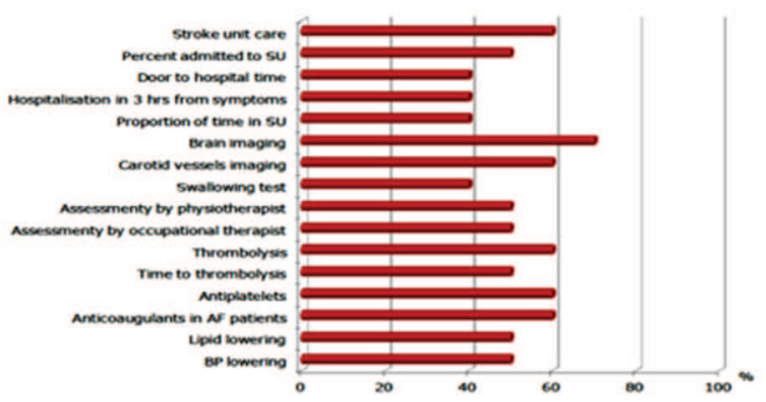

Fig. 1. Quality indicators in the treatment of acute stroke on a national level in the participating counties (Francesca Romana Pezzella, Stroke Unit, AO S Camillo-Forlanini, Rome, Italy - ESO Conference, 2015 - Glasgow)

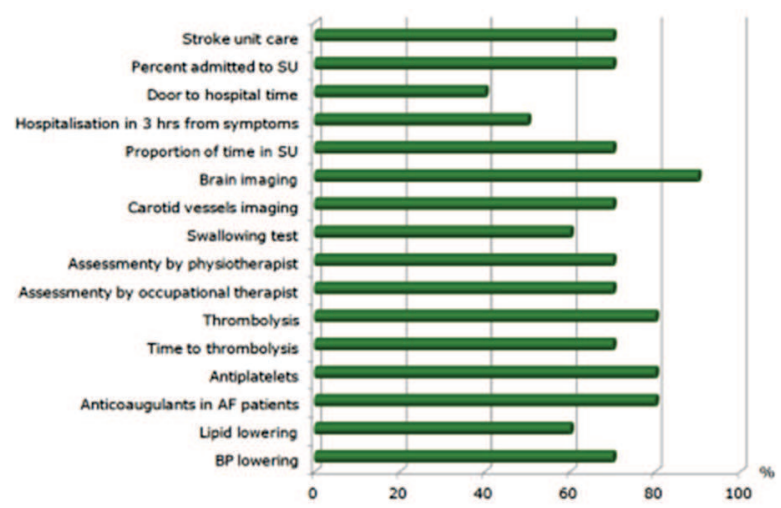

Fig. 2. Quality indicators in the treatment of acute stroke on a regional level in the participating countries (Francesca Romana Pezzella, Stroke Unit, AO S Camillo-Forlanini, Rome, Italy - ESO Conference, 2015 - Glasgow)

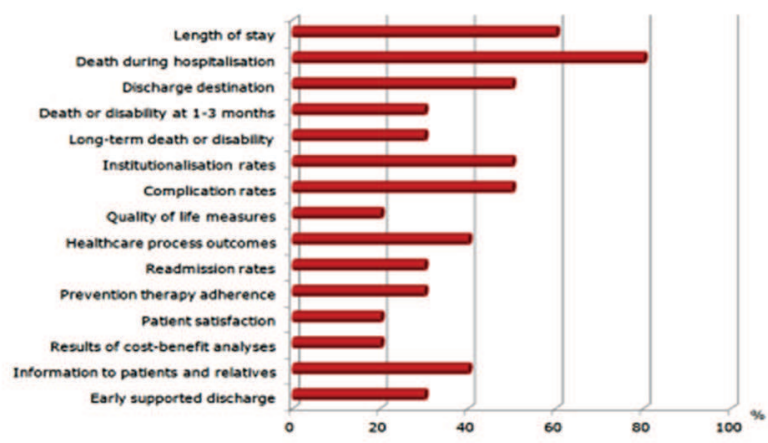

Fig. 3. Quality indicators in the treatment of acute stroke on a national level in the participating countries (Francesca Romana Pezzella, Stroke Unit, AO S Camillo-Forlanini, Rome, Italy - ESO Conference, 2015 - Glasgow)

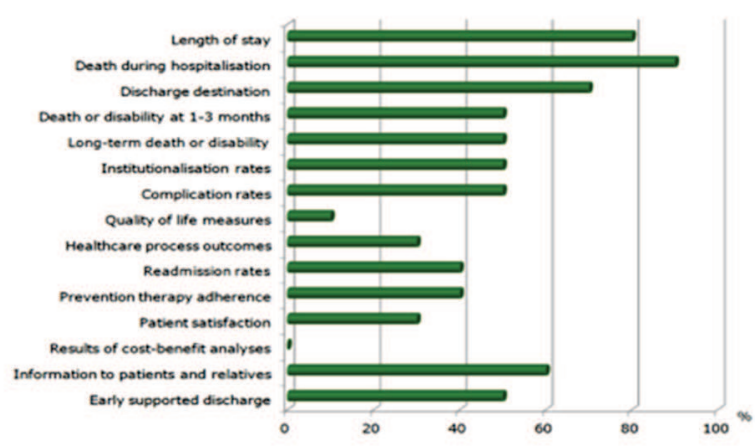

Fig. 4. Quality indicators in the treatment of acute stroke on a regional level in the participating countries (Francesca Romana Pezzella, Stroke Unit, AO S Camillo-Forlani-

ni, Rome, Italy - ESO Conference, 2015 - Glasgow)

There are differences in the applied quality indicators in the treatment of acute stroke on both regional and national levels in the participating countries (figures 1, 2, 3, 4).

\section{DISCUSSION}

According to WHO of 1987:

"In health care establishments, quality is an approach which is called to guarantee each and every patient the aggregate of diagnostic and therapeutic activities which will ensure the best possible outcome in view of health in accordance with the current state of the medical science, with the best assessment for same outcome, and the lowest possible iatrogenic risk and a deep satisfaction from the procedures, outcomes and human contact within the health care system".

EU health policies are based on the best scientific proof, grounded in verifiable, scientific data, information and the necessary tests. In the first, and later, in the second health programs, the EU adopted the integrated approach to health care - intersector cooperation and activities for rendering health information, a fast response to health threats and promoting health through factors crucial for health. The membership of Bulgaria in the EU and the responsibility of the state relating to this membership, the changing public relations and economic conditions in the country and the necessity for guaranteeing a high level of health care, require analysis and assessment of the situation within the healthcare system, as well as updating of the guidelines on providing sustainable development and efficiency (18). 
AIS treatment has progressed greatly recently. A large number of innovative methods have been implemented in an attempt to improve therapeutic practices. International research shows an ever increasing efficiency in the treatment of ischemic stroke at the specialised units for treatment of stroke as compared to conventional therapy practices; their prognostication use is deemed irrefutable. The organisation of medical care and mainly the succession of the different stages of medical aid are very important - diagnostics and treatment in the acute stage, secondary prevention and early rehabilitation $(19,20,21)$.

The implementation of multidisciplinary approaches in AIS patients leads to decreased mortality, disability and a better clinical outcome of the disease $(22,23)$.

Of utmost importance for the increase of quality of service of stroke patients is the development of diagnostic-therapeutic algorithms (protocols) which give important information about all the key resources necessary for the planning of hospital practice on all levels, and at the same time enhancing the cooperation between practice and theory while at the same time accounting for hospital practice quality.

Introducing disease severity levels as a basic measurement principle. The defining of the medical parameters of disease severity is a prerequisite for using exact characteristics of the case-mix approach when classifying and measuring the hospital product. The introduction of therapeutic goals and outcome of the disease, relating to the severity will specify the data about the types of the treated patients (24).

The defining and monitoring of standardized quality indicators aimed at different aspects of clinical practice can be exceptionally useful in daily clinical practices (25). Further research is needed in view of defining unified quality indicators in clinical practice as regards acute ischemic stroke patients.

\section{REFERENCES}

1. Meretoja A, Roine RO, Kaste M, Linna M, Juntunen M, Erilä T. Stroke monitoring on a national level: PERFECT Stroke, a comprehensive, registrylinkage stroke database in Finland. Stroke. 41, 2010: 2239-2246.

2. Tityanova E., Velcheva I., Andonova S. Stroke in Bulgaria: Current Issues. Neurosonolgy and Cerebral Hemodynamics, 11, 2015: 7-13
3. European Stroke Organisation. Guidelines for management of ischaemic stroke and transient ischaemic attack. Stroke 33, 2002: 2850-2857

4. Adams HP, del Zoppo G; Alberts MJ. Guidelines for the early management of adults with ischemic stroke: Aguideline from the American Heart Association/American Stroke Association Stroke Council, Clinical Cardiology Council, Cardiovascular Radiology and Intervention Council, and the Atherosclerotic Peripheral Vascular Disease and Quality of Care Outcomes in Resaerch Interdisciplinary Working Groups.scientific statement from the Stroke Council of the American Stroke Association. Stroke 38, 2007: 1655-1711.

5. Ferrari J, Knoflach M, Kiechl S, Willeit J, Matošević B. For the Austrian Stroke Unit Registry Collaborators. Stroke Thrombolysis: Having More Time Translates Into Delayed Therapy. Stroke 41, 2010: $2-5$.

6. Petrova Z., Chamov K., Gladilov St. Quality in Health Care. Contemporary Dimensions and Trends. Health Media Group, Sofia, 2008.

7. European Stroke Organisation (ESO) Executive Committee; ESO Writing Committee. Guidelines for management of ischaemic stroke and transient ischaemic attack 2008. Cerebrovasc Dis 25, 2008: 457-507

8. Petrova Z., Genev St. Health System Management. Health Media Group, Sofia, 2013.

9. Heuschmann PU, Kolominsky Rabas PL, Kugler C. Qualitätssicherung in der Schlaganfall-Behandlung: das Basismodu der Arbeitsgemeinschaft Deutscher Schlaganfall-Register (ADSR).Gesundheitswesen 62, 2000: 547-552.

10. Abilleira S, Ribera A, Sánchez E, Tresserras R, Gallofré $\mathrm{M}$. The second stroke audit of catalonia shows improvements in many, but not all quality indicators. Int J Stroke 7, 2012: 19-24.

11. Heuschmann PU, Biegler MK, Busse O. Development and implementation of evidence-based indicators for measuring quality of acute stroke care: the Quality Indicator Board of the German Stroke Registers Study Group (ADSR). Stroke 37, 2006: 2573-2578.

12. Kjellstrom T, Norrving B, Shatchkute A. Helsingborg Declaration 2006 on European stroke strategies. Cerebrovasc Dis. 23, 2007: 231-241.

13. Olsen TS, Langhorne P, Diener HC, Hennerici M, Ferro J, Sivenius J. European Stroke Initiative Rec- 
ommendations for Stroke Management-update 2003. Cerebrovasc Dis. 16, 2003: 311-337.

14. Wellwood I, Wu O, Langhorne P, McKevitt C, Di Carlo A, Rudd AG. Developing a tool to assess quality of stroke care across European populations: the EROS Quality Assessment Tool. Stroke. 42, 2011: 1207-1211.

15. Wiedmann S, Norrving B, Nowe T. Variations in quality indicators of acute stroke care in 6 European countries: the European Implementation Score (EIS) Collaboration. Stroke 43, 2012: 458-463.

16. Abilleira $S$, Gallofré M, Ribera A, Sánchez E, Tresserras R. Quality of in-hospital stroke care according to evidence-based performance measures: results from the first audit of stroke, Catalonia, Spain. Stroke. 40, 2009: 1433-1438.

17. Grube MM, Dohle C, Djouchadaret D. Evidencebased quality indicators for stroke rehabilitation. Stroke 43, 2012: 142-146.

18. Alberts MJ, Latchaw RE, Selman WR. Brain Attack Coalition. Recommendations for comprehensive stroke centers: a consensus statement from the Brain Attack Coalition. Stroke 36, 2005: 1597-1616.

19. Asplund K, Hulter Åsberg K, Appelros P, Bjarne D, Eriksson M, Johansson A. The Riks-Stroke story: building a sustainable national register for quality assessment of stroke care. Int J Stroke. 6, 2011: 99-108.

20. Eissa A, Krass I, Bajorek B. Optimizing the management of acute ischaemic stroke: a review of the utilization of intravenous recombinant tissue plasminogen activator (tPA). Journal of Clinical Pharmacy and Therapeutics. 37, 2012: 620-629.

21. Eissa A, Krass I, Bajorek B. Barriers to the utilization of thrombolysis for acute ischaemic stroke. Journal of Clinical Pharmacy and Therapeutics 23, 2012: 211-221.

22. Heuschmann PU, Busse O, Wagner M. Frequency and care of stroke in Germany. Akt Neurologie 37, 2010: 333-340.

23. Nabavi DG, Ringelstein EB, Faiss J. Regional and national stroke units in Germany: amended certification criteria. Nervenarzt 83, 2012: 1039-1052.

24. Nimptsch U, Mansky T. Trends in acute inpatient stroke care in Germanyan observational study using administrative hospital data from 2005-2010. Dtsch Arztebl Int 109, 2012: 885-892.
25. Reeves MJ, Parker C, Fonarow GC, Smith EE, Schwamm LH. Development of stroke performance measures: definitions, methods, and current measures. Stroke. 41, 2010: 1573-1578. 